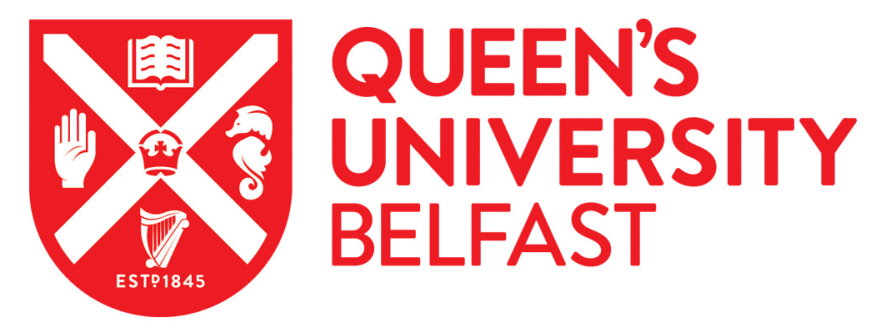

\title{
Reducing the cadmium, inorganic arsenic and dimethylarsinic acid content of rice through food-safe chemical cooking pre-treatment
}

Pogoson, E., Carey, M., Meharg, C., \& Meharg, A. A. (2020). Reducing the cadmium, inorganic arsenic and dimethylarsinic acid content of rice through food-safe chemical cooking pre-treatment. Food Chemistry, 338, 127842. https://doi.org/10.1016/j.foodchem.2020.127842

Published in:

Food Chemistry

Document Version:

Peer reviewed version

Queen's University Belfast - Research Portal:

Link to publication record in Queen's University Belfast Research Portal

Publisher rights

Copyright 2020 Elsevier Ltd.

This manuscript is distributed under a Creative Commons Attribution-NonCommercial-NoDerivs License

(https://creativecommons.org/licenses/by-nc-nd/4.0/), which permits distribution and reproduction for non-commercial purposes, provided the author and source are cited.

\section{General rights}

Copyright for the publications made accessible via the Queen's University Belfast Research Portal is retained by the author(s) and / or other copyright owners and it is a condition of accessing these publications that users recognise and abide by the legal requirements associated with these rights.

Take down policy

The Research Portal is Queen's institutional repository that provides access to Queen's research output. Every effort has been made to ensure that content in the Research Portal does not infringe any person's rights, or applicable UK laws. If you discover content in the Research Portal that you believe breaches copyright or violates any law, please contact openaccess@qub.ac.uk. 
1 Reducing the cadmium, inorganic arsenic and dimethylarsinic acid

2 content of rice through food-safe chemical cooking pre-treatment

3

5 Pogoson E., Carey M., Meharg C.* \& Meharg A.A*

6

7

8

Institute for Global Food Security, Queen's University Belfast, Biological Sciences Building,

9 Chlorine Gardens, Belfast, Northern Ireland, BT9 5DL

10

11

12

*corresponding authors: A.A. Meharg (aa.meharg@qub.ac.uk) and Caroline Meharg

(caroline.meharg@qub.ac.uk)

14

15

16

17

18

19

20

21

22 


\section{Abstract}

Cadmium, inorganic arsenic and, potentially, dimethyl arsenic acid are carcinogens widely elevated in rice. Here it was identified that the food-safe and common cadmium chelator citric acid efficiently removed cadmium from intact grain via pre-soaking procedure, while also reducing arsenic species. A twostep pre-soaking stage was developed whereby rice was first incubated, at ambient temperature, in $1 \mathrm{M}$ citric acid for 12 hours, and then in $1 \mathrm{M}$ calcium carbonate for another 12 hours, the latter step to neutralize $\mathrm{pH}$, followed by cooking. When 10 different individual types of rice were processed in such a way this resulted in removal rates of $79 \%$ for cadmium, $81 \%$ for inorganic arsenic and a $66 \%$ for DMA. The technology is particularly suitable for bulk food processing and could be deployed in the most cadmium and arsenic impacted regions where rice is a staple.

\section{Keywords}

arsenic, cadmium, DMA, rice 


\section{Introduction}

Paddy rice is a major source of exposure, globally, to the carcinogen and nephrotoxin cadmium (Clemens et al., 2013; EFSA, 2012; Shi et al., 2020) and the carcinogen inorganic arsenic (EFSA, 2009; Carey et al., 2020). Rice can also be elevated in dimethylarsinic acid (DMA) (Carey et al. 2020), which is thought to be a carcinogen (Yamamoto et al., 1995). Cadmium and arsenic are specific problems for low-land rice cultivation as paddy management involves anaerobic and aerobic cycling of soils, regulated by irrigation. Under reduced conditions, i.e. flooding, arsenic species are mobilized in soil and assimilated by roots, while it is the aerobic periods that cause cadmium assimilation and mobilization (Arao et al., 2009).

There are regions of the world where cadmium and inorganic arsenic are particularly elevated in rice, such as the base metal mining zone of South East China, which is also nationally a major rice production region (Williams et al., 2009). Concentrations of both cadmium and arsenic routinely exceed $0.2 \mathrm{mg} / \mathrm{kg}$, the Chinese standard, in Guangdong, Hunan and Fujian provinces (Cai et al., 2019; Nengchang et al., 2018; Williams et al., 2009; Xiao et al., 2018; Zeng et al., 2015), the concentration that the EU state should not be exceeded for cadmium (Commission Regulation, 2006) and inorganic arsenic (Commission Regulation, 2015). As the populace of such regions depend on rice as a dietary staple, and there being few alternatives, this makes rice production highly problematic. Thus, if cadmium and inorganic arsenic can be reduced in rice then large production regions rice output can be made safer.

Post-harvest processing of rice can be used to lower grain inorganic arsenic, primarily parboiling (Rahman et al., 2019) or cooking (Carey et al., 2015; Raab et al., 2009), but such 
simple cooking technologies are ineffective for cadmium and DMA. A high water:rice volume removes up to $45 \%$ (Raab et al., 2009), while percolating rice with boil water removes up to 70-80\% (Carey et al., 2015), of grain inorganic arsenic. Inorganic arsenic is predominantly present in rice as arsenite, which is uncharged and relatively soluble at neutral $\mathrm{pH}$ (Meharg and Zhao, 2012), rice grain itself being circa. neutral. Cadmium is doubly charged and has a high affinity to polar functional groups in biological matrices (Huo et al, 2016; Wu et al., 2016; Zou et al., 2019). DMA has a $\mathrm{pK}_{\mathrm{a}}$ of 6.2 (Meharg and Zhao, 2012), requiring acid conditions to become neutrally charged. Therefore, more astringent methods are needed to remove cadmium and DMA from rice.

Cadmium is readily complexed with dicarboxylic acids, which include cheap and common food ingredients such as citric acid (Huo et al, 2016; Wu et al., 2016; Zou et al., 2019). Huo et al. (2016) found that the separation of rice into starch and protein using an alkaline extraction method, and then followed by washing the protein isolate with citric acid, efficiently removed the cadmium from the extracted rice protein. Zou et al. (2019) found that citric acid could remove cadmium from bran, while Wu et al. (2016) established that citric acid could be used to reduce this element from brown rice flour. Citric acid treatment also was found to reduce lead (Behrouzi et al., 2020a) and total arsenic (Behrouzi et al., 2020b) from rice grain. Here we optimise procedures to remove cadmium from intact rice using citric acid, and then developed processes to neutralize the subsequent acidification of $\mathrm{pH}$. The consequences for inorganic arsenic and DMA, and for mineral nutrients, was also determined. 


\section{Materials and Methods}

\subsection{Experiments}

Packaged commercial rice grain was purchased from retail stores in Belfast, Northern Ireland. Ten polished rice samples were tested including Italian, Thai and basmati. One Italian arborio rice was selected on which to conduct initial optimization trials. The developed procedure was then validated on the other grains. Throughout, a rice to preparation/cooking solution ratio of 1:5 was used as this has been shown to very effective in decreasing inorganic arsenic (Carey et al., 2015).

For the initial experiments rice ( $50 \mathrm{~g}$ ) was accurately weighed from the rice packet (dry weight was calculated separately), and then soaked in $250 \mathrm{ml}$ of a range of concentrations of both citric and ascorbic acid $(0,0.0001,0.001,0.01,0.1$ and $1 \mathrm{M})$ in a $400 \mathrm{ml}$ flat bottomed Pyrex beaker for 12 hours, pre-determined by experimentation to be optimized soaking time, in triplicate. After soaking, the rice samples were rinsed thoroughly with double distilled, deionized Millipore water and then cooked on a traditional hotplate for approximately 10 mins till soft. The excess water was discarded, and samples were analysed for cadmium, arsenic species, and a range of mineral nutrients and $\mathrm{pH}$. A second phase of experiments identified how to neutralize rice after citric acid treatment. Rice sample weights, soaking ratios and preparation procedures were identical to the initial phase, but following citric acid treatment and rinsing, a second 12 hour soaking stage, followed by rinse, was tested where calcium carbonate $(0,0.1$ and $1 \mathrm{M})$ was used, and then the rice finally cooked. Once optimal cooking procedures were identified, then the 10 different rice samples were prepared. This involved a 12 -hour soak in $1 \mathrm{M}$ citric acid, then a rinse; a $12 \mathrm{~h}$ soak in $1 \mathrm{M}$ calcium carbonate, and then a rinse, and then cooking till rice was prepared. Throughout, uncooked (i.e. straight 
out of the packet) and traditionally cooked rice (straight from packet and cooked in a 1:5 rice to purified water ratio) were also conducted to test the efficacy of the modified procedures.

\subsection{Chemical analysis}

117 For all experiments, uncooked and cooked grain rice was freeze-dried overnight. Samples were then milled to a powder using a Retch PM 100 rotary ball-mill using a zirconium oxide lined vessel and grinding balls, at $500 \mathrm{rpm}$ for 4 mins. Samples were then analysed for total elementals by ICP-MS and XRF, arsenic speciation by ion-chromatography-ICP-MS, and pH.

For ICP-MS total elemental analysis, milled samples were accurately weighed $(0.1 \mathrm{~g})$ into $50 \mathrm{ml}$ polypropylene centrifuge tubes. To each tube, $2 \mathrm{ml}$ of concentrated $69 \%$ Aristar nitric acid was added and left to sit overnight. Analytical grade hydrogen peroxide $(2 \mathrm{ml})$ was then added and allowed to outgas for 15 mins. Samples were prepared in batches of 40 and included a blank and a rice CRM, NIST 1568b rice flour which is certified for a wide range of both trace and macro elements. Microwave digestion in a CEM MARS 6 instrument was then carried out under conditions $95^{\circ} \mathrm{C}$ for $5 \mathrm{~min}$ held for $10 \mathrm{~min}, 135^{\circ} \mathrm{C}$ for $5 \mathrm{~min}$ held for $10 \mathrm{~min}$ and $180^{\circ} \mathrm{C}$ for $5 \mathrm{~min}$ held for $30 \mathrm{~min}$. Total elements were then measured using the Thermo ICAP Q ICPMS in direct acquisition mode, with rhodium as an internal standard. All elements reported in results were present in the existing in calibration standards (SPEX Europe), as well as in with LoDs (Table 1).

For inorganic arsenic speciation, $\sim 0.1 \mathrm{~g}$ of powdered rice was accurately weighed into $50 \mathrm{ml}$ polypropylene centrifuge tubes to which $2 \mathrm{ml}$ of dilute $69 \%$ Aristar nitric acid was added and 

1568b Rice flour which is certified for arsenic species. Microwave digestion was conducted under similar conditions to the table above. Following digestion, the digestate was then diluted to $10 \mathrm{ml}$ with distilled water and $700 \mathrm{ul}$ was transferred to a $2 \mathrm{ml}$ polypropylene vial, to which $0.7 \mathrm{ul}$ of analytical grade hydrogen peroxide was added. The rice solution was then run on a Thermo Scientific IC5000 Ion Chromatography system with a Thermo AS7, 2×250 mm column (and a Thermo AG7, 2x50 mm guard column) with a gradient mobile phase ( $\mathrm{A}: 20 \mathrm{mM}$ ammonium carbonate, B: $200 \mathrm{mM}$ ammonium carbonate- starting at $100 \% \mathrm{~A}$, changing to $100 \% \mathrm{~B}$, in a linear gradient over 15 mins) interfaced with the Thermo ICAP Q ICP-MS which monitors $\mathrm{m} / \mathrm{z}^{+} 75$, using helium gas in collision cell mode. The resulting chromatogram was compared with authentic standards DMA, inorganic arsenic, monomethylarsonic acid (MMA), trimethyl arsenic oxide (TMAO), tetramethyl arsonium (TETRA) and arsenobetaine (AB).

A bench top XRF (Rigaku CG) was used to analyse additional elements using the milled rice samples. Batches of 9 samples were analysed in triplicate with CRM NIST 1568b rice flour. Approximately $3 \mathrm{~g}$ of each rice sample was weighed into prepared XRF cups lined with proline film and pressed using a PANAPRESS. Following XRF analysis, elements present in the CRM with good analytical recoveries (50-150\%) were reported (Table 1).

To measure the rice $\mathrm{pH}$ after pre-soaking step and subsequent cooking, a 2:1-part water to rice ratio slurry was made and the $\mathrm{pH}$ meter swirled until a steady $\mathrm{pH}$ reading was obtained. 
159 Half limit of detection (LoD) was used for elemental concentrations below LoD. LoDs are 160 reported in Table 1. Statistical analysis was conducted using two-way ANOVA in MiniTab 18 161 as well as sample t-test in where applicable.

162 


\section{Results}

164 Cadmium in the rice investigated ranged by over an order-of-magnitude, from 0.006 to 0.077 $\mathrm{mg} / \mathrm{kg}$ (Figure 1). Total arsenic in the grain had a similarly large range, from 0.02 to 0.095 $\mathrm{mg} / \mathrm{kg}$. Chemical analysis of rice grains before and after pre-soaking treatment and cooking showed that citric acid pre-soaking resulted in a maximal $81 \%$ removal of cadmium at $1 \mathrm{M}$ concentration $(P<0.0001)$, with the efficacy of removal increasing as acid concentration rose

(Fig. 1). Decrease in cadmium was linear with log10 increase in citric acid concentration $(\mathrm{P}<0.0001)$. Citric acid inhibited total arsenic removal, as compared to the control, with a linear increase with $\log 10$ increase in citric acid $(P<0.0001)$. However, even at $1 \mathrm{M}$ citric acid, the highest concentration, $1 / 3$ of total arsenic was removed as compared to the uncooked grain. The $\mathrm{pH}$ after soaking in citric acid showed a progressive decrease from a $\mathrm{pH}$ of 6.4 to 2.5 (Fig. 1). investigated. Trials found that the rice required a 12-hour soak for maximum $\mathrm{pH}$ neutralization to occur, with calcium carbonate being the most effective (Fig. 2). The $\mathrm{pH}$ increased linearly with time. Soaking the citric acid treated rice in calcium carbonate linearly $(P=0.0001)$ increased $\mathrm{pH}$ up to 7.5 at 12 hours.

The optimal procedures for removing cadmium were a soaked for 12 hours in $1 \mathrm{M}$ citric acid, thoroughly rinsed, and then soaked for 12 hours in $1 \mathrm{M}$ calcium carbonate, followed by subsequent boiling in water (Fig. 3). For the 10 rice types this sequence, on average caused cadmium to be reduced $>60 \%$, with a standard error of $4.6 \%$, of the starting raw rice grain. 
concentration (5\%), while treatment with citric acid alone caused an $80 \%$ reduction in cadmium. The calcium carbonate soak caused cadmium in citric acid treatment to be doubled, probably due to trace cadmium concentrations in the calcium carbonate, given that the rice in the citric acid treatment was very low in cadmium. Median changes in grain cadmium, comparing water, citric acid and citric acid plus carbonate were significant $(P=0.0001)$ when analysed using Kruskal-Wallis analysis. For total arsenic, cooking in 5:1 water to rice ratio reduced arsenic to $66 \%$ of uncooked grain, but further reductions were seen when a citric acid pre-soak was used (46\%) and citric acid and calcium carbonate in combination (38\%). These medians were significantly different from each other at $\mathrm{P}=0.05$.

To explore the arsenic data further, speciation was conducted (Figure 4). Inorganic arsenic dominated species, with inorganic arsenic averaging $0.08 \mathrm{mg} / \mathrm{kg}$, and DMA $0.033 \mathrm{mg} / \mathrm{kg}$. Cooking in a 5:1 water to rice ratio reduced inorganic arsenic by $\sim 60 \%$, from 0.08 to 0.033 $\mathrm{mg} / \mathrm{kg}$, with further reductions on citric acid treatment (to $0.02 \mathrm{mg} / \mathrm{kg}$ ) and citric acid plus calcium carbonate $(0.015 \mathrm{mg} / \mathrm{kg})$, a maximum $82 \%$ reduction, on average. These percentage differences were highly significant when tested by Kruskal-Wallis analysis $(P<0.0001)$. The DMA did not alter concentration on cooking alone, but a 50\% reduction was observed on citric acid, and a $66 \%$ reduction on calcium carbonate treatment, from a starting concentration of $0.032 \mathrm{mg} / \mathrm{kg}(\mathrm{P}<0.0001)$.

Five-to-one water to rice cooking ratios decreases phosphorus by a $2 / 3$, zinc by $1 / 3$ and potassium by $5 / 6$ across the 10 rice types tested, with all these differences being significant at $\mathrm{P}<0.0001$ (Figure 5). Citric acid pre-soak strips out more potassium, zinc and sulphur, but not phosphorus and calcium to any major consequence. The calcium carbonate soak has little 
211 effect on all nutrients examined except for calcium, which was fortified in cooked grain by 2-

212 orders of magnitude $(\mathrm{P}<0.0001)$. Calcium carbonate also restored $\mathrm{pH}$ of the rice from a mean

213 level of 2.4 in citric acid alone treated rice to 7.3 when the citric acid treatment was followed

214 by a subsequent calcium carbonate soak $(P<0.0001)$. 


\section{Discussion}

Here we showed that simple soaking treatments in citric acid and then calcium carbonate reduced cadmium and inorganic arsenic by $80 \%$ (60\% for cadmium after $\mathrm{pH}$ neutralization), and DMA by $2 / 3$, while fortifying with calcium by 2 -orders of magnitude. This means that rice from highly impacted mining regions, typified by the S.E. China mining belt (Cai et al., 2019; Nengchang et al., 2018; Williams et al., 2009; Xiao et al., 2018; Zeng et al., 2015), can be made much safer for human consumption.

The loss of essential nutrients observed here, as compared to conventional cooking, conforms with the study by Mwale et al. (2018) which reported that the use of excess water in rice cooking for arsenic removal resulted in a significant loss of all essential elements except iron, selenium and copper. Similarly, Carey et al. (2015) highlighted a $53 \%$ potassium loss following the use of percolating boiling water for rice cooking to remove arsenic. Fortifying nutrients into grain is common practise, and in many regions of the globe is used as standard to improve the health of the populace (Dwyer et al., 2015). We propose that such fortification can be conducted at the neutralization stage as it was very effective for calcium here.

It is well understood that inorganic arsenic is readily stripped from rice by pre-soaking in and cooking in large volumes of water to rice, while DMA and cadmium are not (Carey et al. 2015; Raab et al., 2009). So, having procedures to remove DMA, and particularly, cadmium from rice is an important advance. The $\mathrm{pK}_{\mathrm{a}}$ for $\mathrm{DMA}$ is 6.2 , and this may explain its enhanced mobility when the $\mathrm{pH}$ is dropped, i.e. it becomes fully protonated and, thence, neutral and mobile (Meharg and Zhao, 2012). Caruso et al. (2001) found that DMA and inorganic arsenic could be decreased in freeze-dried apple samples that were treated with a solution including 
acetic (extraction efficiency range $79 \%$ to $117 \%$ ). For inorganic arsenic a low pH per se does not enhance mobilization due to a $\mathrm{pK}_{\mathrm{a}}$ of 9.2 for arsenite (Meharg and Zhao, 2012), so the reason why lower $\mathrm{pH}$ mobilizes arsenite is not known in the experiments reported here.

Cadmium is readily complexed by dicarboxylic acids, such as citrate (Huo et al., 2016; Wu et mobility and leaching under the protocols developed here. Wu et al. (2016) trialled citric, malic and tartaric acid for the removal of cadmium from brown rice and found citric acid to be optimal, removing up to $94 \%$. They noted that quality of brown rice was not affected. However, they only used up to $0.06 \mathrm{M}$, as opposed to $1 \mathrm{M}$ here that removed only up to $80 \%$ but causing a considerable drop in $\mathrm{pH}$. Presumably, this was due to Wu et. (2016) using flour as opposed to intact grain, with intact grain being more intractable. A very highly liquid:solid ratio was optimal, 12:1, with lower ratios extracting less. They did not test for mineral nutrients. Huo et al. (2016) removed $95 \%$ of cadmium from rice protein extracts using citric acid at $0.5 \mathrm{M}$ citric acid in a 6:1 ratio. They had trialled a wide range of acids, food safe and non-food safe, (hydrochloric, lactic, maleic, malic, oxalic, phosphoric and tartaric), and found that concentrations above $0.2 \mathrm{M}$ were required to be effective, with enhanced removal up to $0.6 \mathrm{M}$. Liquid:solid ratio had to be above 6 for effective removal. $\mathrm{pH}$ and loss of mineral nutrients were not recorded. Similarly, $0.15 \mathrm{M}$ citric acid at a 10:1 liquid:solid ratio was effective at removing $94 \%$ of cadmium from rice bran (Zou et al., 2019). The overall chemical structure of the bran was not greatly affected, while vitamin E compounds and rice analogues were slightly enriched. The vitamin B suite was not analysed, and neither were mineral nutrients or $\mathrm{pH}$. They found that citric acid opened the structure of the rice (using SEM), and that there was little difference in FTIR spectra. We conducted SEM and FTIR on our samples, 
including the calcium carbonate treated samples, and concluded the same that treatment did not greatly affect the structure of grain (data not shown). As well as acids, neutral deep eutectic solvents, which act as micelles, were used to efficiently extract cadmium (>90\%) from rice flour, again with a large solvent:solid ratio, 12:1, being most effective (Huang et al., 2018). The consequences on arsenic species, and nutrients and vitamins were not explored.

Previous approaches to cadmium removal from rice have used microbial fermentation. Incubation with Bacillus and yeast species resulted in $81 \%$ removal of cadmium Zhang et al. (2017). However, it required 60 hours of fermentation for optimum cadmium removal and resulted in a decrease in protein content. Similarly, Zhai et al. (2019) found that fermentation of rice with Lactobacillus plantarum strains resulted in a 93\% cadmium removal, reducing protein, lipid and ash contents of rice grain. Although effective at cadmium removal, these post-harvest approaches are labour and capital intensive and thus may not appeal to rice producers, manufacturers and consumer. It is like that fermentation is effective in cadmium removal due to increased acidity and to the opening up of rice structure, making cadmium more leachable.

A more radical approach to reducing cadmium exposure from rice grain was developed by Sun et al. (2020). They proposed to reduce gut availability of cadmium, derived from rice, by model. These included tannic acids, titanium dioxide and zinc glutamate, amongst others, achieving a $10-98 \%$ reduction in gut bioavailability of cadmium. However, their findings may be limited in translation to humans in that human gut microbiology is more complex, and that dietary interventions rely on palatability/acceptability. 
288 The procedures outlined here have their limitations, and studies still needs to be conducted 289 on food acceptability/palatability, and potential products for the rice cooked in this way may 290 need developing. Refinement of these procedures lies in the hands of food technologists.

291 However, we have established that cadmium, in tandem with inorganic arsenic and DMA, can 292 be removed using food-safe chemical procedures. Also, we have ascertained that subsequent 293 neutralization is also a very useful step, not just for readjusting $\mathrm{pH}$, but also for any potential 294 fortification (calcium in this case). 
Arao, T., Kawasaki, A., Baba, K., Mori S., Matsumoto S. (2009) Effects of water management

on cadmium and arsenic accumulation and dimethylarsinic acid concentrations in Japanese rice. Environmental Science Technology, 43, 9361-9367.

Behrouzi, R., Marhamatizdeh, M.H., Raavilar, V., Rastegar, H., Shoeibi, S. (2020a) Effects of the pre-cooking process using acetic acid and citric acid on lead concentration in rice. Polish Journal Environmental Studies, 29, 545-551.

Behrouzi, R., Marhamatizdeh, M.H., Shoeibi, S., Raavilar, V., Rastegar, H. (2020b) Effects of the pre-cooking process using acetic acid and citric acid on residual arsenic content in rice. Polish Journal Environmental Studies, 29, 553-559.

Cai K., Yu Y., Zhang M., Kim K. (2019) Concentration, source and total health risks of cadmium in multiple media in densely populated areas, China. International Journal of Environmental Research Public Health, 16, 2269. e0131608. doi: 10.1371/journal.pone.0131608.

Carey, M., Meharg, C., Williams, P.N., Marwa, E., Jiujin, X., Gomes Farias, J., De Silva, P.M.C.S., 
A.J., Moreno-Jimenez, E., Carbonell-Barrachina, Á.A., Triwardhani, E.A., Pandianga, F.I., Haris, P.I., Lawgali, Y.F., Sommella, A., Pigna, M., Brabet, C., Montet, D., Njira, K., Watts, M.J., Meharg, A.A. (2019) Global Sourcing of low-inorganic arsenic rice grain. Exposure Health doi.org/10.1007/s12403-019-00330-y

334

Caruso J., Heitkemper D., B'Hymer C. (2001) An evaluation of extraction techniques for arsenic species from freeze-dried apple samples. Analyst, 126, 136-140.

337 preventing slow cadmium poisoning. Trends Plant Science, 18, 92-99.

content/EN/TXT/?uri=CELEX:02006R1881-20150521 content/EN/TXT/?uri=CELEX:32015R1006

Dwyer, J., Wiemer, K., Dary, O., Keen, C., King, J., Miller, K., Philbert, M., Tarasuk, V., Taylor, C., Courtney Gaine, P., Jarvis, A., Bailey, R. (2014) Reviews from ASN EB Symposia. Fortification and Health: Challenges and Opportunities 1-4. DOI: 10.3945/an.114.007443. 

food-chain. EFSA J, 980, 1-139.

European Food Safety Authority (2012) Cadmium dietary exposure in the European population. EFSA J 10, 2551.

Huang, Y., Feng, F., Chen, Z., Wu, T., Wang, Z. (2018) Green and efficient removal of cadmium from rice flour using natural deep eutectic solvents. Food Chemistry, 244, 260-265. washing protein isolate. Journal Food Science, 81, T1567-T1584.

Meharg, A.A., Zhao, F.J. (2012) Arsenic and rice. Springer, Netherlands.

366

Mwale, T., Rahman, M., Mondal, D. (2018) Risk and benefit of different cooking methods on essential elements and arsenic in rice. International Journal Environmental Research Public Health, 15, 1056. DOI: 10.3390/ijerph15061056.

370

371 Nengchang, C., Xiaoxia, Z., Yuji, Z. (2018) Heavy metal concentrations in rice from Guangzhou and associated health risks. Journal Resources Ecology, 9, 85. 
Raab, A., Baskaran, C., Feldmann, J., Meharg, A.A. (2009) Cooking rice in a high water to rice ratio reduces inorganic arsenic content. Journal Environmental Monitoring, 11, 41-44.

Rahman, H., Carey, M., Hossain, M., Savage, L., Islam, M.R., Meharg, A.A. (2019) Modifying the parboiling of rice to remove inorganic arsenic, while fortifying with calcium. Environmental Science Technology, 53, 5249-5255.

380

Shi. Z., Carey, M., Meharg, C., Williams, P.N., Signes-Pastor, A.J., Triwardhani, E.A., Pandianga,

F.I., Campbell, K., Elliott, C., Marwa, E., Xia, J., Gomes Farias, J., Nicoloso, F.T., De Silva,

P.M.C.S., Lu, Y., Norton, G., Adomako, E., Green, A.J., Moreno-Jimenez, E., Carbonell-

Barrachina, Á.A., Haris, P.I., Lawgali, Y.F., Sommella, A., Pigna, M., Brabet, C., Montet, D., 385 Njira, K., Watts, M.J., Hossain, M., Islam, M.R., Tapia, Y., Orport, C., Meharg, A.A. (2019) Rice grain cadmium concentrations in the global supply-chain. Exposure Health doi.org/10.1007/s12403-020-00349-6.

388

Sun, S., Zhou, X., Li, Y., Xia H., Li, Z., Zhuang, P. (2020) Use of dietary components to reduce the bio accessibility and bioavailability of cadmium in rice. Journal Agricultural Food

Chemistry. DOI: 10.1021/acs.jafc.0c01582.

392

Williams, P.N., Lei, M., Sun, G., Huang, Q., Lu, Y., Deacon, C., Meharg, A.A., Zhu Y. (2009)

Occurrence and partitioning of cadmium, arsenic and lead in mine impacted paddy rice: 
Wu, Y., He, R., Wang, Z., Yuan, J., Xing, C., Wang, L., Ju, X. (2016) A safe, efficient and simple technique for the removal of cadmium from brown rice flour with citric acid and analysed by inductively coupled plasma mass spectrometry. Analytical Methods, 8, 6313-6322.

400

401

Xiao, G., Hu, Y., Li, N., Yang, D. (2018) Spatial autocorrelation analysis of monitoring data of 402 heavy metals in rice in China. Food Control, 89, 32-37.

403

404

Yamamoto, S., Konishi, Y., Matsuda, T., Murai, T., Shibata, M.A., Matsuiyuasa, I., Otani, S., 405

Kuroda, K., Endo, G., Fukushima, S. (1995) Can induction by an organic arsenic compound, 406 dimethylarsinic acid (cacodylic acid), in F344/DUCRJ rats after pretreatment with 5 carcinogens. Cancer Research, 55, 1271-1276.

408

Zeng, G., Wu, H., Liang, J., Guo, S., Huang, L., Xu, P., Liu, Y., Yuan, Y., He, X., He, Y. (2015)

Efficiency of biochar and compost (or composting) combined amendments for reducing $\mathrm{Cd}$,

$\mathrm{Cu}, \mathrm{Zn}$ and $\mathrm{Pb}$ availability, mobility and ecological risk in wetland soil. RSC Advances, 5, 3454134548.

Zhai, Q., Guo, Y., Tang, X., Tian, F., Zhao, J., Zhang, H., Chen, W. (2019) Removal of cadmium from rice by Lactobacillus plantarum fermentation. Food Control, 96, 357-364.

Zhang, L., Lei, Q., Cheng, Y., Xie, Y., Qian, H., Guo, Y., Chen, Y., Yao, W. (2017) Study on the removal of cadmium in rice using microbial fermentation method. Journal Food Science, 82, $1467-1474$. 
421 Zou, Y., Zhang, X., Ju, X., Wang, Z., Wu, Y., Yuan, J., Chen, W., He, R. (2019) Effect of removing 422 cadmium with citric acid one the physiochemical and microstructure properties of rice. Food 423 Control, 98, 290-296.

424 
426 Table 1. Recoveries of elements and arsenic species from CRM NIST 1568b, rice flour, along

427 with limits of detection (LoD).

428

429

\begin{tabular}{|c|c|c|c|c|}
\hline \multirow[t]{4}{*}{ element } & CRM & CRM & CRM & S.E.M \\
\hline & reported & recovery & recovery & \\
\hline & conc. & conc. & (\%) & \\
\hline & (mg/kg) & (mg/kg) & & \\
\hline
\end{tabular}

\begin{tabular}{l|l|l|l|l|l}
\hline cadmium & 0.0224 & 0.0162 & 72.3 & 0.002 & 0.006 \\
\hline arsenic & 0.285 & 0.222 & 77.8 & 0.018 & 0.03 \\
\hline potassium & 1282 & 1026 & 80 & 4.206 & - \\
\hline zinc & 19.4 & 17.7 & 91 & 1.298 & 1.785 \\
\hline calcium & 118 & 113 & 96 & 5.004 & - \\
\hline sulphur & 1200 & 1020 & 85 & 3.086 & - \\
\hline phosphorus & 1530 & 1591 & 104 & 86.801 & 19.953 \\
\hline inorganic arsenic & 0.090 & 0.0830 & 92.2 & 0.001 & 0.0004 \\
\hline DMA & 0.180 & 0.155 & 86.1 & 0.002 & 0.0004 \\
\hline
\end{tabular}

430

431 
Figure 1. The effect of 12 hour soaking in molar concentrations of citric and ascorbic acid and then subsequent cooking in pure water, on cadmium and arsenic content and $\mathrm{pH}$ of Arborio rice. Each acid concentration was conducted in triplicate. Individual samples are shown.
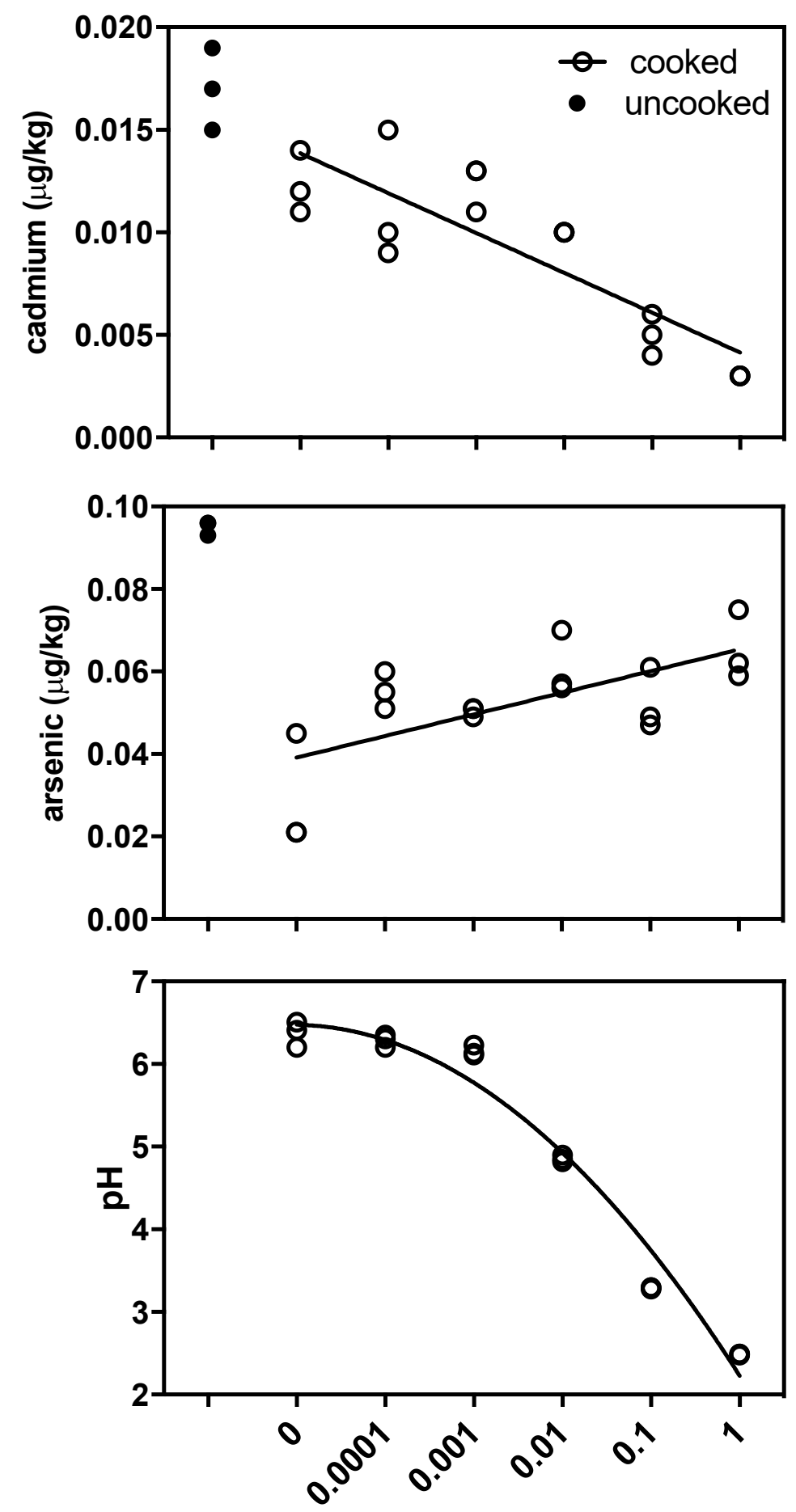

citric acid conc. (M) 
Figure 2: The effect of calcium carbonate, calcium chloride and calcium citrate on the $\mathrm{pH}$ boiling. Each salt concentration was conducted in triplicate. Individual samples are shown.

441

442

443
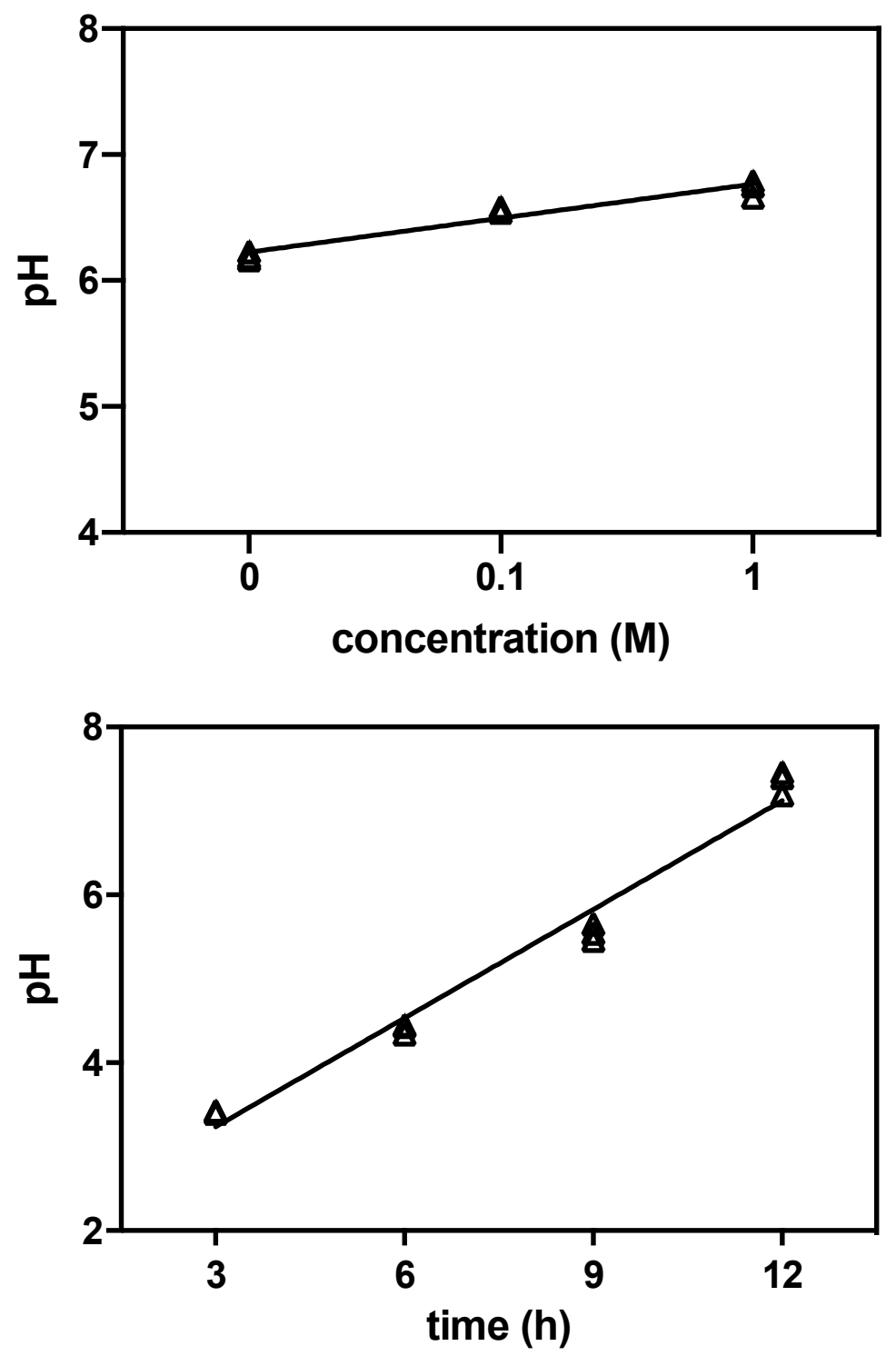

444 
Figure 3: The effect of rice pre-soaking treatments on 10 polished rice types after a 12-hour

447 pre-soak in citric acid, and another 12-hour soak in calcium carbonate and subsequent boiling,

448 with a 12-hour pre-soaking in water as control, on the cadmium and inorganic arsenic acid

449 content. The insert shows the median and 25th percentiles for remaining cadmium. Means

450 and standard errors are shown in the main graph, averages in the insert.

451
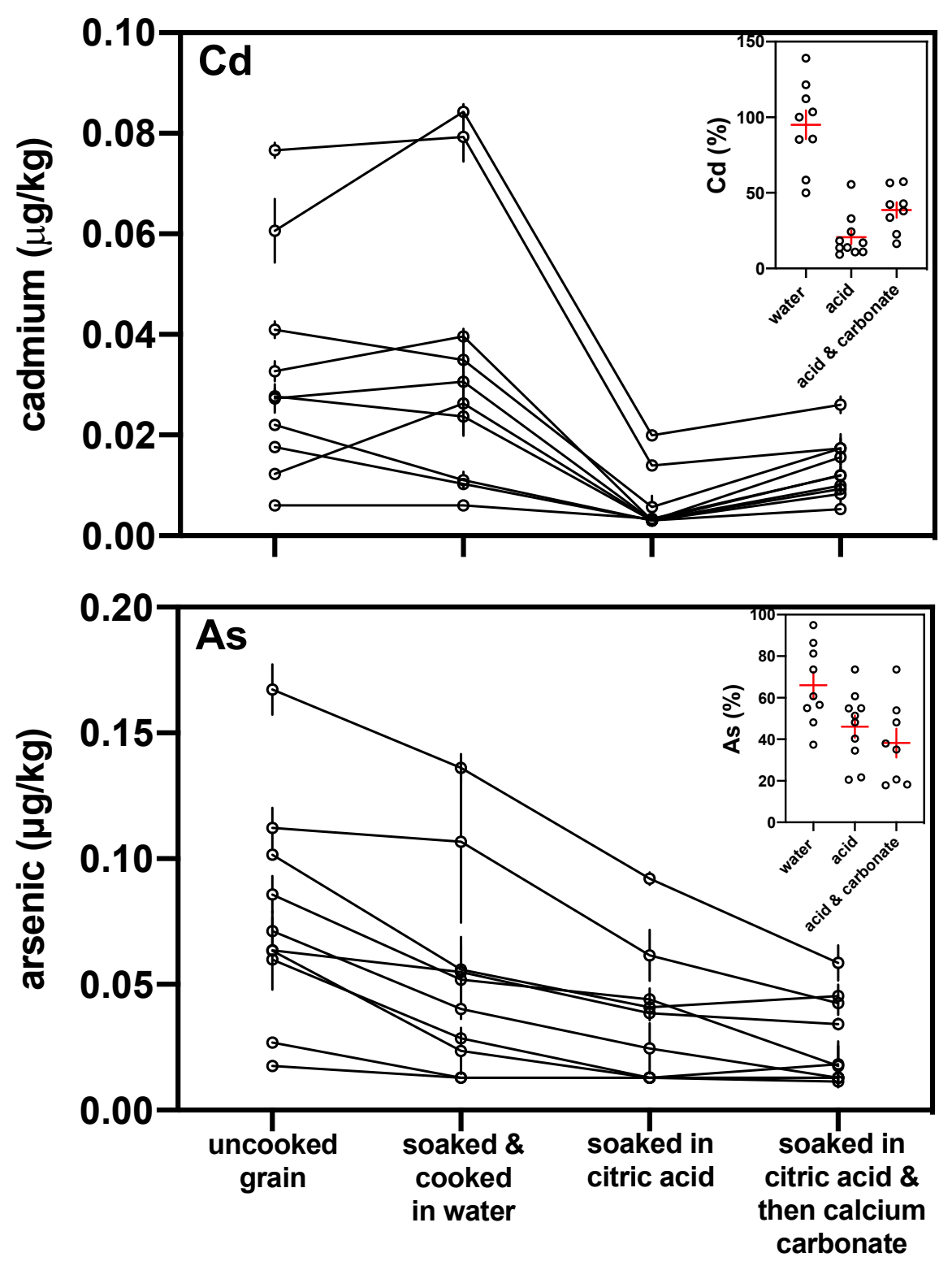
454 Figure 4: The effect of treatment of polished rice types after a 12-hour pre-soak of white rice 455 grain in citric acid, and another 12-hour soak in calcium carbonate and boiling, with a 12-hour pre-soaking in water as control on the arsenic species. Each aligned point represents triplicate

457 analysis and an average, plus and minus the standard error, presented.

458

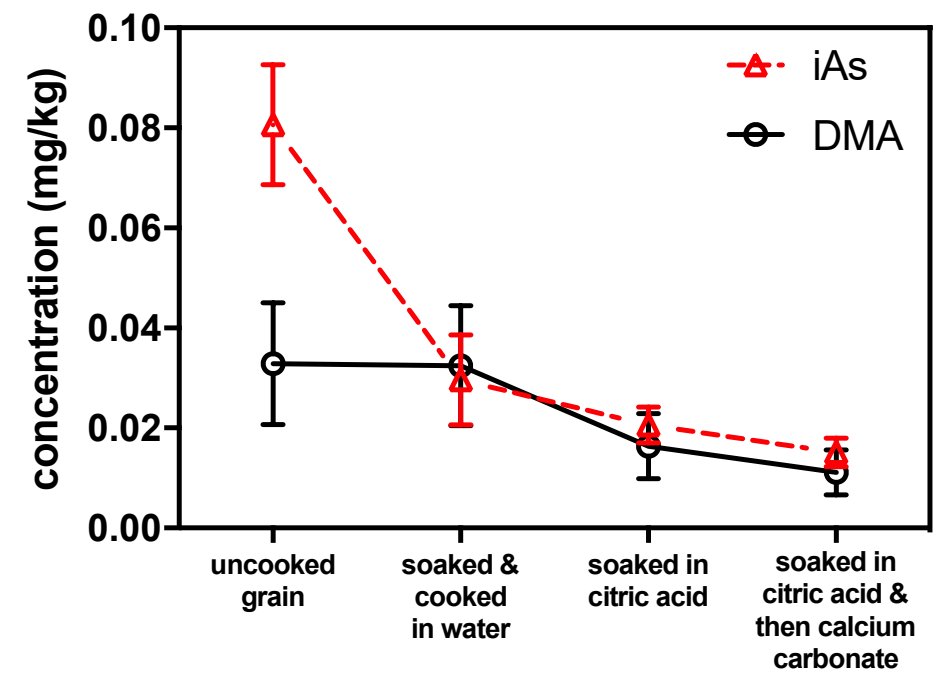

459

460

461 
Figure 5: Multi-elemental content (potassium, zinc, calcium, sulphur, chlorine and

463 phosphorus) of polished rice grains. Rice samples were soaked in citric acid for 12 hours and

464 then in calcium carbonate for another 12 hours with subsequent boiling with a 12-hour pre-

465 soaking in water as control and analysed in triplicate. Each point represents triplicate analysis

466 plus and minus standard error of the mean..

467
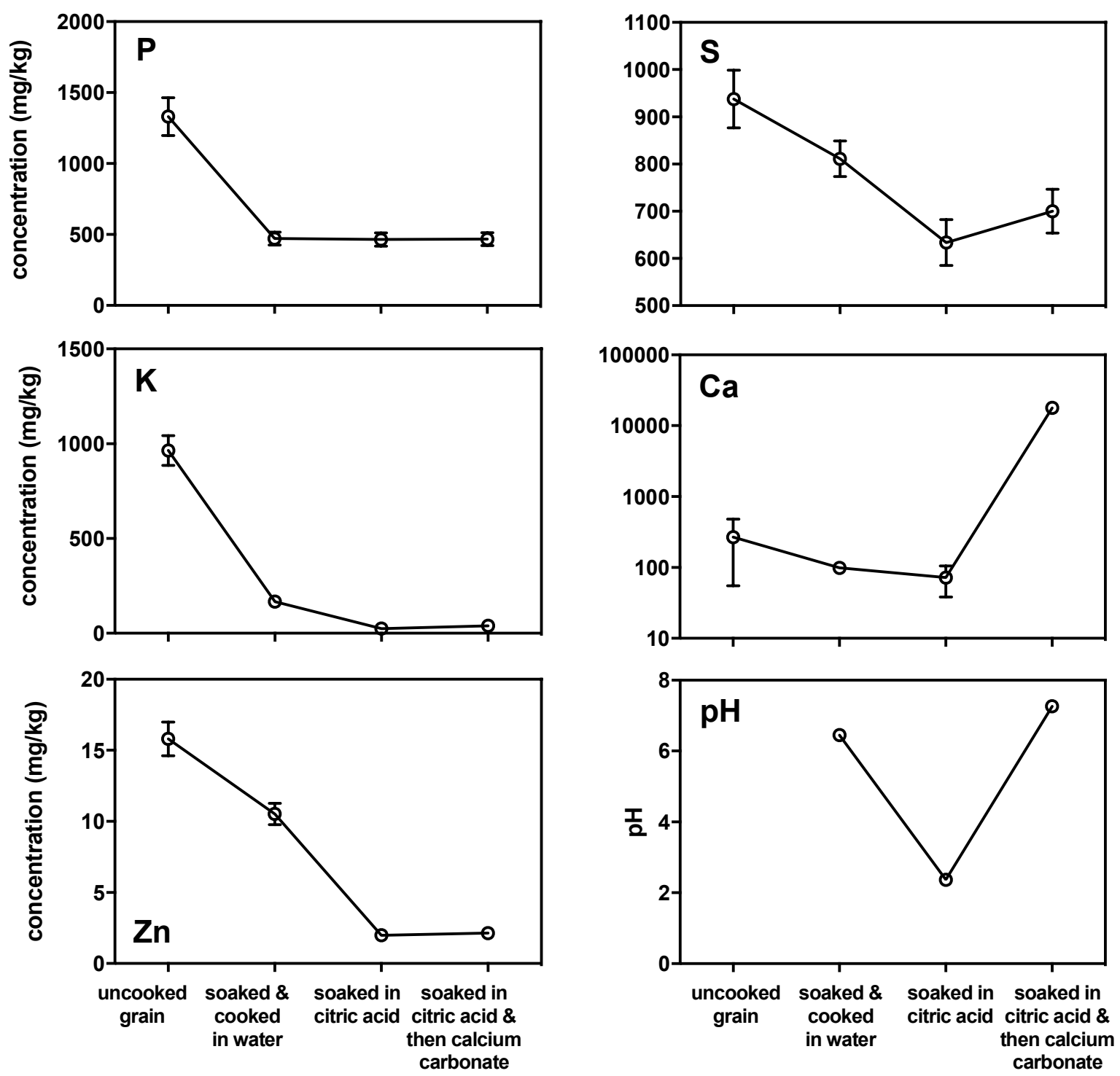